\title{
Dido y Eneas en el Quijote de 1615
}

\author{
JUAN DIEGO VILA \\ Instituto de Filología Clásica \\ Facultad de Filosofía y Letras \\ Universidad de Buenos Aires
}

\begin{abstract}
RESUMO: Ainda que o conhecimento, por parte de Cervantes, das versões da Eneida do século de ouro espanhol seja algo comumente creditado pela crítica, nâo tem havido estudos que avaliem adequadamente a indole de tal reelaboração. Neste artigo centrar-nos-emos na paródia dos amores de Dido e Enéias, que Cervantes realiza, na segunda parte de sua obra, através das personagens Altisidora e Dom Quixote. Estruturada ao longo de três momentos-chave e encadeada ao tratamento de outros dois mitos clássicos - o de Teseu e Ariadne e o de Orfeu e Eurídice esta análise pretende uma releitura que leve em conta o valor da obra virgiliana na conformação deste romance.
\end{abstract}

PALAVRAS-CHAVE: Cervantes, Dom Quixote, Virgilio, Eneida, Dido e Enéias, literatura comparada.

Puesto que la influencia de Virgilio en tratadistas y autores del Siglo de Oro Español fue de un gran espectro, muy dificilmente la crítica cervantina pueda rechazar la existencia de una "materia virgiliana"1 en el Quijote. El reconociminto de la impronta de las obras de "el mantuano" 2 , fundamentalmente la de la Eneida, no se reduce al ámbito del circuito comunicativo autor-lector (hecho que nos autoriza a hablar, por ejemplo, de reelaboraciones paródicas de obras virgilianas). Puede decirse,sin temor a equívocos, que Virgilio y su Eneida han sido parte no sólo de la cultura de Cervantes y su público sino también de la de sus personajes de ficción.

En el Quijote de 1615 muchos son los personajes que mencionan a Eneas ${ }^{3}$ o que aluden a su historia, la que por otra parte, no aparece circunscripta al ámbito artísticoliterário.

De retorno a su aldea, ya vencido por el caballero de la Blanca Luna, Don Quijote y Sancho se apean en un mesón donde le sirven de guadameciles unas sargas viejas pintadas. En una de ellas "estaba la historia de Dido y de Eneas, ella sobre una alta torre, como que hacía de señas con una media sábana al fugitivo huésped" 4 .

Quizás el mejor modo de probar hasta que punto este plano de los personajes del Quijote es un universo virgiliano sea recordar que en una de las burlas ducales, la condesa Trifaldi hace un empleo retórico de un "verso" de la Eneida (II, 6-8). 
El "quis talia fando temperet a lacrymis" 5 adquiere relevancia no sólo por el hecho de ser una cita en latín, sino también porque, tal como la emplea la dueña Dolori$\mathrm{da}$ - al referir la historia de la infanta Antonomasia, don Clavijo, la reina Maguncia y el gigante Malambruno - da toda la impresión de haber ingresado al habla castellana como expresión cristalizada por lo recurrente de su uso.

La obra de Arturo Marasso ${ }^{6}$ ya ha demostrado ampliamente como un sinnúmero de secuencias de la novela son interpretables a partir de un conocimiento profundo, de Cervantes, de los autores clásicos?.

Quizás lo único que puede consurársele a este crítico, que cotejó las primeras ediciones en lengua romance de Virgilio ${ }^{8}$, la de Gregorio Hernanández de Velazco de 1555 y la de Diego López de 1600, sea el no haber encarado, con profundidad deseable, una interpretación que contemplara, en toda su magnitud, este brillante juego intertextual.

Las farsas que Altisidora monta en la segunda parte del Quijote presentan, incluso para el lector ingenuo, la necesidad de contraponer a la historia de Don Quijote la del troyano fundador de Roma.

La parodia del trágico amor de Dido y el hijo de Venus se da, en el Quijote, a través de tres momentos, presentados, cada uno de ellos, en tres farsas distintas:

- El enamoramiento en la del capítulo 44

- El abandono en la del capítulo 57

- El reencuentro infernal en la del capítulo 69

Debe recordarse, por último, que, como en la segunda y tercera farsa se parodian las historias de Teseo y Ariadna y de Orfeo y Eurídice, éstas deben ser contrapuestas a la de Dido y Eneas.

De este modo lo que, en una primera lectura, puede parecer una "sinfonia virgiliana" ha de transformarse en un polifonía mítica. Polifonía mítica que no debe ser deshechada a la hora de intentar una interpretación del Quijote y, en particular, de la evolución del héroe en esta segunda parte.

\section{El enamoramiento (primera farsa: II, 44)}

Sancho ha partido a su gobierno en la Insula Barataria y un solitario Don Quijote en el castillo ducal ya ha comenzado a sentir su ausencia. Sin poder dormir "abrió un poco la ventana de una reja que daba sobre un hermoso jardin"10 en el cual Altisidora y Emerencia, doncellas de la duquesa, llevan a cabo su primera representación. Un diálogo y un romance, entonado por la primera, configuran toda esta dramatización como una parodia de ciertos fragmentos del canto IV de la Eneida.

La confesión de Dido a Ana y los consejos de esta a su hermana son, sin lugar a dudas, el fragmento de texto que, colocado en un trasfondo, permite a Cervantes elaborar esta parodia.

Altisidora comienza diciendo: 
No me porfies ¡Oh Emerencia! que cante, pues sabes que desde el punto que este forastero entró en este castillo y mis ojos le miraron, yo no sé cantar, sino llorar [...] en vano sería mi canto si duerme y no despierta para oírle este nuevo Eneas, que ha llegado a mis regiones para dejarme escarnida 11 .

Si bien puede decirse que sus palabras evidencian la intención de entroncarse con uma muy conocida tópica amorosa no debe pensarse que en la presentación de una situación propia de cuento popular agotan éstas su cometido.

El lector debe advertir que las menciones de "este forastero" que llega a los dominios regidos por una mujer, de ese "mis ojos le miraron", y de "este nuevo Eneas" precisan una historia de amor (la de Dido y Eneas) que debe ser perfectamente distinguida de cualquier otra arquetipica.

En el canto IV de la Eneida - recordemos - Dido decía:

Anna soror, quae me suspensam insomnia terrent!

Quis nouus hic nostris succesit sedibus hospes!

Quem sese ore ferens! quam forti pectore et armis! ${ }^{12}$

Anna fatebor enim, miseri post fata

Sychaei

Conjugis, et sparsos fraterna caede

Penate,

Solus hic inflexit sensus, animumque

labantem

Impulit: agnosco veteris vestigia flammae ${ }^{13}$

En ambas obras la confesión de amor por el forastero de las heroínas se ve correspondida por palabras alentadoras. En el Quijote es Emerencia quien dice:

No des en eso, Altisidora amiga - respondieron -; que sin duda la duquesa y cuantos hay en esta casa duermen, si no es el señor de tu corazón y el despertador de tu alma; porque ahora sentí que abría la ventana de la reja de su estancia, y sin duda debe de estar despierto; canta, lastimada mía, en tono bajo y suave, al son de tu harpa, y cuando la duquesa nos sienta, le echaremos la culpa al calor que hace ${ }^{14}$.

palabras análogas a las de Ana a su hermana:

Anna refert: O luce magis dilecta sorori,

Solane perpetua maerens carpere iuventa,

Nec dulces natos, Veneris nec premia noris?

Id cinerem aut Manes credis curare sepultos?

Esto: aegram nulli quondam flexere mariti,

Non Lybiae, non ante Tyro, despectus Iarbas 


\section{Ductoresque alii, quos Africa terra triumphis \\ Diues alit: placitone etiam pugnabis amori? ${ }^{15}$}

La respuesta de Ana hace que Dido se permita asumir ese amor:
His dictis incensum animum inflammauit amore, Spemque dedit dubiae menti, soluitque pudorem ${ }^{16}$

Efectos semejantes surten los consejos de Emerencia en la "malferida Altisidora",17

No esta en eso el punto !Oh Emerencia!- respondió la Altisidora-, sino en que no querría que mi canto descubrise mi corazón, y fuese juzgada de los que no tienen noticia de las fuerzas poderosas de amor por doncella antojadiza y liviana. Pero venga lo que viniere, que más vale vergüenza en cara que mancilla en corazón ${ }^{18}$.

A continuación, "afinada la harpa"19 Altisidora entona un romance. A lo largo de diecinueve cuartetas de neto corte burlesco Altisidora pretende demostrar que, asi como Dido sabe de Eneas y su fama, ella es conocedora de la de Don Quijote. Recordemos, a tal efecto, la segunda cuarteta o la séptima:

Caballero el más valiente que ha producido La Mancha más honesto y más bendito que el oro de Arabia! $!^{20}$

Muy bien puede Dulcinea, doncella rolliza y sana, preciarse de que ha rendido a una tigre y fiera brava ${ }^{21}$

sólo al final de esta extensa composición Altisidora revelará su identidad:

Estas y otras gracias miras son despojos de tu aljaba; desta casa soy doncella, y Altisidora me llaman 22

No resulta superfluo recordar que Dido, ya en el canto I de la Eneida estaba al tanto del linaje de Eneas:

Quis genus Aeneadum, quis Troiae nesciat urbem, Virtutesque, uirosque, aut tanti incendia belli ${ }^{23}$

Quis te, nate dea, per tanta pericula casus 
Insequitur? Quae uis immanibus applicat oris?

Tune ille Aeneas, quem Dardanio Anmchisae

Alma Venus Phrygii renuit Simoentis ad undam ${ }^{24}$

El que Don Quijote, concluido el romance diga para si "- Que tengo de ser tan desdichado andante, que no ha de haber doncella que me mire que de mi no se enamore" ${ }^{25}$ nos recuerda la imagen de la cierva herida y el cazador ignorante por medio de la cual Virgilio describe el amor por Eneas que en Dido nace sin que el hijo de Venus sea consciente de ello o se lo proponga:

Uritur infelix Dido totaque uagatur

Urbe furens, qualis coniecta cerua sagitta

Quam procul incautam nemora inter Cresia fixit

Pastor agens telis, liquitque uolatile ferrum

Nescius; illa fuga siluas satusque peragrat

Dictaeos; haeret lateris letalis arundo ${ }^{26}$

Cabe destacar, por último, que si en la Eneida el amor de Dido por Eneas es un fuego ciego:

At regina, graui iamdudum saucia cura,

Vulnus alit uenis, et caeco carpitur igni ${ }^{27}$

El que Don Quijote ha despertado en Altisidora es - segun nos lo refiere la decimocuarta cuarteta del romamce entonado — de una intensidad increíble:

No mires de tu Tarpeya

este incendio que me abrasa,

Nerón manchego del mundo,

ni le avives con tu saña ${ }^{28}$

\section{Eneas/Don Quijote — Dido/ Altisidora}

La historia de Eneas, hijo de Venus y Anquises, no siempre estuvo asociada a la de Dido y a la de la fundación de Roma.

En tanto figura legendaria de la cual Homero ${ }^{29}$ y los ciclos épicos ${ }^{30}$ dan cuenta, su historia se encuentra sometida, desde tiempo inmemorial, a sutiles variantes que, con el transcurso de los años, fueron tomando incongruentes las distintas versiones.

Si se tiene en cuenta que las legendarias historias de Dido y Eneas recién son relacionadas entre sí por medio de la obra de Nevio La Guerra Púnica ${ }^{31}$ se apreciará 
con claridad por cuanto tiempo cada personaje gozó de "vida independiente" y cuan expuesta a críticas se podía encontrar esta innovación.

La acusación de traición que pesaba sobre la fama de Eneas, la localización de la nueva ciudad que fundara con los exiliados de la destruída Troya, la posibilidad de un encuentro con Dido ${ }^{32}$, fueron aquellos puntos sobre los cuales los historiadores contemporáneos y posteriores al mantuano asentaron sus discrepancias.

Si bien la Eneida de Virgilio se constituyó en piedra basal para la fama ulterior de ambos personajes no por ello esta versión dejó de suscitar controversias, y, de hecho, ya desde los primeros siglos de la era cristiana se perfilaron dos versiones claramente definidas, una que acepta los dichos de Virgilio y otra - formada a partir de Justino y otros autores cristianos - que reduce al grado de ficticio todo lo que aquel autor presentara ${ }^{33}$.

De larga data es en España la presencia del tema troyano: dos inscripciones sepulcrales del sigilo XI en latin $^{34}$ y una alusión de los Anales Toledanos de 1219 en lengua castellana $^{35}$, dan prueba de ello.

No obstante, tal como lo prueba Amancio Labandeira ${ }^{36}$, la reelaboración del tema que realizaran los autores medievales trajo aparejada una degradación de sus personajes. El comportamiento de los mismos ha pasado a regirse - en tiempos previos al renacimiento - del estatuto real de la época grecorromana al estatuto familiar y doméstico del período medieval. Al autor medieval sólo le interesa la dimensión ejemplar que pueda encontrar en estos personajes por lo qual, la mayoría de las veces, Dido y Eneas se ven reducidos a un hombre que engaña y a una mujer burlada. Además hay que tener en cuenta que en estos escritores de la Edad Media hay una postura eclética frente a las dos versiones de la historia. Un conocimiento profundo de las mismas sólo se logra en tiempos renacentistas, gracias a la tarea de los humanistas y su posición frente a lo clásico grecolatino.

En tiempo de Cervantes la pérdida de autoridad de Justino frente a Virgilio y la modificación de la jerarquía de la castidad entre las virtudes de la mujer posibilitan composiciones como la que don Miguel pone en boca de Altisidora.

Quizás uno de los rasgos esenciales de Eneas sea el de ser un héroe fundacional. Eneas no es un simple héroe que recorre los mares en busca de aventuras; su misión, fundar una nueva Troya, le confiere un halo sacro. Dificilmente se encuentre mejor caracterización que la que de sí mismo hace Eneas:

Sum pius Aeneas, raptos qui ex hoste Penates

Classe veho mecum, fama super aethera notus.

Italiam quaero patriam et genus ab love summo ${ }^{37}$.

Como el hijo de Anquises el Don Quijote de esta segunda parte ya tiene su fama hecha; al igual que él - he aquí un punto clave — ha de volver a fundar algo que se ha perdido: Eneas una nueva Troya, Don Quijote la caballería andante.

Dido para Eneas es uno de los obstáculos más arduos que los dioses colocan en su camino. El amor de esta reina fenicia exiliada en Cartago conlleva el mismo grado de 
perversión y degradación que el de Altisidora por Don Quijote. Eneas para ser digno de la misión que los dioses le han conferido debe realizar un sacrificio de sus deseos individuales. Don Quijote, a su vez, debe mantenerse firme y no ceder a los requiebros de Altisidora pues como todo caballero andante el ya tiene su dama.

Don Quijote, a diferencia de Eneas, no necesita, por cierto, que ningún dios le recuerde su misión y las exigencias de esta:

¿Que tenga de ser tan corta de ventura la sin par Dulcinea del Toboso, que no lo han de dejar a solas gozar de la incomparable firmeza mía! [...] Dejad, dejad a la miserable que triunfa, se goce y ufane con la suerte que Amor quiso darle en rendirle mi corazón y entregarle mi alma [...] para ser yo suyo, y no de otra alguna me arrojó la naturaleza al mundo. Llore, o cante, Altisidora; desespérese Madama por quien me aporrearon en el castillo del moro encantado, que yo tengo de ser de Dulcinea, cocido o asado, limpio, bien criado y honesto, a pesar de todas las potestades hechiceras de la tierra ${ }^{38}$.

Atisidora - personaje degradado - es una contrafigura burlesca de Dulcinea, ideal de pureza y perfección. Análoga relación guardarán para el lector de la Eneida los personajes de Dido y Lavinia, quienes, para la cosmovisión del siglo de Augusto, encarnarán los comuptores lujos orientales y la austeridad y pureza de las primitivas costumbres latinas.

\section{El abandono (segunda farsa: II, 57)}

Suzanne Guillou-Varga ${ }^{39}$ en su estudio sobre la relación entre los mitos, las mitografias y la obra lírica de Garcilaso de la Vega, Herrera y Góngora reconoce que en el empleo literario de los mitos se produce una deconstrucción de los mismos. Los motivos que encuertra para que esto suceda - con los cuales concordamos plenamente son los siguientes:

1. Mientras la fuente mítica suele ser de expansión lineal, la obra literaria (particularmente el poema) tiende a la condensación conceptual.

2. En las recreaciones de los líricos del Siglo de Oro se suele tomar un momento autónomo que evoque una situación ejemplar.

3. La deconstrucción de la fuente mítica favorece la gracia de su empleo y el poder alusivo del mito.

Algo análogo sucede con esta historia mítica de Dido y Eneas en el Quijote. La elección de tres momentos representativos de la historia de estos personajes responde a los tres motivos expuestos precedentemente.

Consecuentemente, en estas farsas de Altisidora, la parodia mítica es introducida ante los ojos del lector por mecanismos muy precisos ${ }^{40}$.

En el romance burlesco de Altisidora del capitulo 57 de la segunda parte es dable distinguir distintos planos alusivos. En un primer nivel se puede colocar la mención del 
"fugitivo Eneas" 41 personaje con el cual - como ya hemos visto - los lectores del Siglo de Oro estaban ampliamente familiarizados. De segundo grado son aquellas marcas textuales que responden al mundo del texto colocado en el trasfondo para la parodia. En este caso el tercer y cuarto verso de la tercer cuarteta:

que Diana vio en sus montes

que Venus miró en sus selvas ${ }^{42}$

o la sexta cuarteta:

Ilevaste dos mil suspiros

que, a ser de fuego pudieran

abrasar a dos mil Troyas,

si dos mil Troyas hubiera ${ }^{43}$

cumplen la función de advertir al lector que se está llevando a cabo una parodia mítica. Menos evidentes que el primer nivel (mención de autores, títulos de obras, personajes) o que el segundo (referencia a contenidos discursivos o imaginarios propios de una obra) son las indicaciones de tercer grado. En ellas si bien el texto de trasfondo no parece precisado, la situación no deja de ser paródica. En las farsas de Altisidora son aquellos elementos que no dependen del enunciado en sí mismo sino de la misma situación de enunciación. Deberia ser indicativo para el lector que Altisidora, una simple doncella, tenga ese don poético que le posibilita componer romances, $o$, como sucede en la primera farsa (II, 44) el que después de afinar el arpa entone un romance en vez de un soneto (como acostumbra hacer Cervantes ${ }^{44}$ ).

Se debe apreciar, por último, que tanto en esta farsa (II, 57) como en la tercera (II, 69) si bien hay marcas textuales claras y precisas que permiten interpretar a cada una como parodia de un mito en particular (Teseo y Orfeo respectivamente), Cervantes logra, por medio de la sobreimposición de referencias a la historia de Dido y Eneas en cada una de ellas, que, lejos de fijar un sentido único, el mito opere como punto de indeterminación textual.

Las referencias al mítico abandono de Teseo a Ariadna colocadas junto a las de la partida de Eneas de Cartago hacen que las marcas míticas, que el texto del romance entonado contiene, se diluyan en la indefinición conformando lo que - sugiero podríamos llamar "protoforma mítica".

"Protoforma mítica" a partir de la cual cada lector podrá actualizar, según sus competencias - es decir, según el conocimiento que tenga de la cultura clásica, particularmente de sus mitos-, una u otra fuente (Teseo, Eneas), ambas a la vez o - en el peor de los $\operatorname{casos}^{45}$ - ninguna de ellas.

$\mathrm{La}$ "protoforma mítica", entonces, es aquella que posibilita que a un mismo texto de Cervantes se le contrapongan diferentes fuentes míticas. La "protoforma mítica" se ve caracterizada, en esta segunda farsa, del siguiente modo: 
1. Caracterización negativa del amante: los vocativos de las primeras cuartetas ("mal caballero", "falso", "monstruo horrendo"46 se corresponden com el "perfide [...] Theseu" 47 de Catulo o con los siguientes versos del canto IV:

Dissimulare etiam sperasti, perfide, tantum

posse nefas tacitusque mea decedere terra? ${ }^{48}$

2. El tema de la huída: el "no huyes de alguna serpiente fiera" 49 nos remite, por un lado, a los siguientes versos de Ovidio y Catulo:

Quine fugit lentos incurvans gurgite remos ${ }^{50}$

"Quo fugis?" exclamo scelerate reverte Theseu ${ }^{51}$

y, por otro, a estas palabras de Dido en el canto IV cuando dice "mene fugis" "52.

Obviamente, no es lo mismo postular que se parodia el abandono de Teseo a Ariadna, o la partida de Eneas. El hijo de Venus y Anquises va a Italia en busca de esa "tierra prometida" para él y su raza. Su partida no es la de un amante desagradecido:

Tandem pauca refert: "Ego te, quae plurima fando

enumerare vales, numquam, regina, negabo

promeritam, nec me meminisse pigebit Elissae,

Dum memor ipse mei, dum spiritus hos regit artus. ${ }^{53}$

Desine meque tuis incendere teque querelis,

Italiam non sponte sequor ${ }^{\text {, } 54}$

En el Quijote esta partida se ve caracterizada por las palabras del narrador de un modo positivo. El palacio ducal era una "nueva Cartago" donde este "Eneas" demoraba su acción.

Cuando Don Quijote se vio campaña rasa, libre y desembarasado de los requiebros de Altisidora, le pareció que estaba en su centro y que los espíritus se le renovaban para proseguir de nuevo el asumpto de sus caballerias ${ }^{55}$.

\section{El reencuentro infernal (tercera farsa : II, 69)}

Con la partida del castillo ducal no se han agotado los encuentos entre Don Quijote y Altisidora. Tampoco, por cierto, ha abandonado Cervantes la parodia del mito de Eneas.

Ya derrotado por el caballero de la Blanca Luna y, por ende, de retorno a su pueblo, Don Quijote y Sancho son apresados por servidores del duque quien, una vez más, ha montado otra farsa para nuestro hidalgo. En ella - como ya visto - se parodia el mito de Orfeo y Eurídice (cf. primera parte de este informe). En este infierno 
virgiliano (pues se nombra a los mismos dos jueces infernales que en la Eneida ${ }^{56}$ Altisidora cumple dos roles, es la Eurídice que Sancho/Orfeo debe rescatar y es, terminada la farsa, una Dido que está en el infierno "por culpa de Eneas" y que se muestra esquiva a la presencia del troyano. Las palabras de Altisidora a Don Qriijote, al ser bajada del túmulo

levantáronse los duques y los reyes Minos y Radamanto, y todos juritos, con Don Quijote y Sancho, fueron a recebir a Altisidora, y a bajarla del túmulo; la cual, haciendo de la desmayada, se inclinó a los duques y a los reyes, y mirando de través a Don Quijote, le dijo:

- Dios te lo perdone, desamorado caballero, pues por tu crueldad he estado an el otro mundo, a mi parecer, más de mil años ${ }^{57}$

se corresponde con la actitud de Dido en el canto VI cuando Eneas, en el infierno, la encuentra:

Infelix Dido, uerus mihi nuntius ergo uenerat exstinctam ferroque extrema secutam! funeris, heu! tibi causa fui! [...] ${ }^{58}$

Siste gradum teque adspectu ne substrahe nostro.

Quem fugis? [... $]^{\text {s9 }}$

Illa solo fixos oculos auersa tenebat, nec magis incepto uultum sermone mouetur, quam si dura silex aut stet Marpesia cautes. Tandem corripuit sese atque inimica refugit in nemus imbriferum, conjux ubi pristinus illi respondet curis aequatque Sychaeus amorem ${ }^{60}$

Es paródico el que, por un lado, en la Eneida sea Eneas quien reconozca su culpa en la muerte de Dido y que, por otro, en el Quijote Altisidora deba informar de ello a Don Quijote.

\section{El mito de Eneas y la polifonía mítica}

Cabe aquí, finalmente, reseñar las funciones que cumple en la estructura discursiva del Quijote la inclusión del mito de Eneas a través de los tres momentos representativos de su amor con Dido.

1. Si se tiene en cuenta el contexto artificioso en el cual el mito es reelaborado, es decir, el de la estancia en el castillo ducal, se verá como la lectura del héroe novelesco (Don Quijote) en relación a un héroe clásico (Eneas) se contrapone a la que los duques han hecho del Quijote de 1605 y a lo que quieren hacer de él: una simple marioneta.. 
Las aventuras pergeniadas por los duques conllevan una visión del artificio degradante y reduccionista. En oposición a estos artificios que son explicables a partir de una copia infinita de prototípicas aventuras de libros de caballería, los episodios elaborados a partir de la parodia del mito de Eneas dan una visión del artificio vivificante.

Lo vivificante de estos artificios no reside tan sólo en el cariz positivo de la trayectoria de Eneas: se debe también a que se coloca a Don Quijote en estrecha relación con un prototípico personaje de la materia troyana de los libros de caballeria. Si en la primera parte la relación de Don Quijote con este mundo legendario se daba a través de otras copias (el Amadis de Gaula, Tirante lo Blanch, Don Belianis, Palmerín de Inglaterra), en esta segunda parte, por medio de esta vinculación directa con Eneas y la materia troyana, al suprimirse los intermediarios, el artificio se vuelve "verdadero" y "artístico"

Recordemos - en apoyo de esta afirmación - lo que Don Quijote dice al contemplar las sargas pintadas:

Notó en las dos historias que Elena no iba de muy mala gana, porque se reía a socapa y a socarrón, pero la hermosa Dido mostraba verter lágrimas del tamaño de nueces por los ojos viendo lo cual Don Quijote dijo:

- Estas dos señoras fueron desdichadísimas, por no haber nacido en esta edad, y yo sobre todos desdichado en no haber nacido en la suya: encontrara a aquestos señores, ni fuera abrasada Troya, ni Cartago destruida, pues con sólo que yo matara a Paris se escusaram tantas desgracias ${ }^{62}$

2. La temática amorosa en el Quijote si bien merece un tratamiento extendido y diverso ${ }^{63}$ no, por ello, deja de ser facilmente esquematizable. Por un lado, Cervantes nos presenta al grueso de los personajes que se guian por pautas de conducta propias del siglo XVII, por el otro, un demodé amante cortés: Don Quijote.

En esta segunda parte no faltan los elementos que nos permiten caracterizar esta posición de Don Quijote frente al amor.

El romance que Don Quijote entona (II, 46$)^{64}$ del cual sobresalen las cuartetas sexta, septima y octava:

El amor recién venido, que hoy llegó y se va mañana, las imágenes no deja bien impresas en el alma.

Pintura sobre pintura, ni se muestra ni señala; y do hay primera belleza, la segunda no hace baza. 


\section{Dulcinea del Toboso \\ del alma en la tabla rasa \\ tengo pintada de modo, \\ que es impossible borrarla ${ }^{65}$.}

es una clara muestra del "platonismo" ${ }^{66}$ de Don Quijote.

Desde esta perspectiva, los tres mitos clásicos analizados además de las funciones discursivas que cumplen, vienen a tematizar dentro de los parámetros "platónicos" el desencuentro amoroso en un nivel sensible.

3. La elección de estos tres personajes míticos legendarios (Orfeo, Teseo, Eneas) responde también al tratamiento del concepto de hombre que la novela propone.

Mucho se ha escrito sobre la evolución del personaje de Don Quijote en esta segunda parte ${ }^{67}$ pero no se ha prestado atención a que esta tan mentada evolución que culmina en el reconocimiento de sí mismo, se debe, esencialmente, al cambio de modelo parodiado. Si en la primera parte del Quijote se parodian los héroes caballerescos, en el Quijote de 1615 éstos seran dejados de lado progresivamente y se tomarán como puntos de referencia figuras de la antigüedad clásica.

Asimismo, estas figuras responden al imaginario cervantino. Teseo, prototípico héroe combatiente, y Orfeo, aquél que conoce por medio del arte el grado sumo de la civilización, se corresponden, en cierta forma, con la arquetípica pareja cervantina del "hombre de armas" y del "hombre de letras" 68 .

Los mitos, a su vez, nos muestran que para Cervantes esta disyuntiva tan suya y de su tiempo (las armas o las letras) sólo es válida si se da por sentada una correcta elección en otra alternativa previa: sćlo es un buen hombre aquel que respeta la dimensión sagrada.

El mito de Eneas contrapuesto a los de Teseo y Orfeo nos presenta a un héroe combatiente y a un héroe cultural que, sobre todas las cosas, es pius.

No es casual, por lo demás, que Cervantes coloque en las mismas secuencias narrativas mitos de polaridad contrapuesta. Cervantes cree en el hombre, cree en lo que hay de bueno en él ${ }^{69}$. Esa fe en la esencia humana es la que lo lleva a dramatizar una historia en la cual la salvación no está ni en España ni en barbería, donde no hay "buenos" y "malos".

Los mitos de Teseo y de Orfeo contrapuestos al de Eneas poetizan una concepción del hombre en la que cada individuo tiene la posibilidad de regenerarse o de degenerar su naturaleza.

4. El mito introduce la polifonía discursiva a partir de la liberación de un imaginario propio no aprehensible si se atiende a sentidos literales. Otro tipo de polifonia, que no necesariamente ha de borrar a la otra, es la que se introduce cuando dos mitos se contraponen. Si bien los mitos de Teseo (II, 57) y Orfeo (II, 69) introducen la polifonía en la medida en que entran en relación con el texto cervantino, estos mitos por el final negativo que tienen en las secuencias que se han elegido (el abandono de Ariadna, la segunda pérdida de Eurídice), remarcan una interpretación negativa que desde el Qui- 
jote se hace de la trayectoria del héroe. Contrapuesto a estos dos mitos, la trayectoria de Eneas polariza las interpretaciones que se pueden hacer del texto con otro sentido.

Si el abandono de Teseo fue una de las máculas que sobre el héroe ateniense más tiempo pesaran y que los ciudadanos de esta polis trataron esforzadamente de borrar, la partida de Eneas es la del héroe que - lejos de mostrarse desagradecido - es, ante todo, respetuoso de los dioses y de la misión que le han conferido: es el pius penatiger.

Mucho más significativa que esta es la apertura de sentidos que se logra con la contraposición de Orfeo a Eneas.

En estas experiencias catábicas la polarización del texto va más allá de una simple resolución feliz o no del episodio. La integración espiritual que conlleva todo descenso a los infiernos y las implicancias que esta catábasis trae para cada héroe son mucho más relevantes.

A Orfeo se ha concedido la posibilidad de volver a la luz aquello que, por disposición divina, no puede retornar a la vida. Orfeo, el artista por excelencia, no ha logrado efectuar una transformación espiritual perfecta, y, por ende, la no maestría de sí mismo ocasionará, por segunda vez, la muerte a Eurídice. Orfeo, de retorno a la tierra, morirá despedazado por las ménades.

Este final destructivo refuerza, desde la parodia, la caída del héroe novelesco. Vencido en la costa de Barcelona, Don Quijote ha sido obligado a abandonar la caballería andante, su razón de ser

Que sólo me contento con que el gran Don Quijote se retire a su lugar un año, o hasta el tiempo que por mi fuere mandado, como concertamos antes de entrar en esta batalla ${ }^{70}$

Junto a esta visión de un Don Quijote "despedazado" interiormente, Cervantes nos entrega la del engrandecimiento humano. Junto a este mito de Orfeo, suerte de "angel caido", Eneas es el "hombre nuevo"71. Eneas ha bajado al mundo subterráneo para encontrarse con su padre muerto, allí, a la par del conocimiento de la esencia de las almas y de su purificación, habrá de operarse en él un transformación espiritual. El conocimiento del mundus hará que retorne a la superficie con nuevas fuerzas. En un modo análogo podemos decir que si el héroe ha muerto, el hombre ha renacido. Este último episodio del mito de Eneas preanuncia el re-conocimiento de Alonso Quijano, el reencuentro con su nombre

Yo fui loco, y ya soy cuerdo; fui Don Quijote de la Mancha, y soy agora, como he dicho, Alonso Quijano el Bueno ${ }^{72}$. 


\section{Notas}

1- El concepto de "materia" les permite a los estudiosos de los libros de caballería catalogar las obras en tres grupos según sus temáticas, estabelecidas, según Jean Bodel en su famoso pareado, del seguiente modo:

Ne sont que trois matieres a nul homme attendant

De France et de Bretagne et de Rome le Grant

Me permito, por ende, emplear en esta crítica del Quijote (obra que parodia a los libros de caballería) tal terminología y distinguir dentro de las fuentes clásicas de Cervantes una "materia virgiliana".

2- José María Pozuelo, en "La recepción de Virgilio en la teoría literaria española del siglo XVI", remarca como Virgilio suscitó en los tratadistas del siglo XVI (Pinciano, Carballo, Herrera, el Brocense) aposiciones y antonomasias muy significativas del valor y autoridad de este autor en temas literarios. Junto a "el mantuano" eran igualmente frecuentes los de "el Poeta", "el Sumo Poeta", "La máxima autoridad".

3- El empleo de la obra de Richard L. Predmore (1938) sirve para demostrar, cómo cuantativa y cualitativamente, la historia de Dido y Eneas es más frecuentemente referida en la segunda parte del Quijote. Si se consultan allí las entradas correspondientes a los nombres "Dido" y "Eneas" se verá cómo la reina de Cartago sólo es mencionada en la segunda parte, y cuántas veces más se inscribe el nombre del troyano en el Quijote de 1615 (7 registros contra dos del Quijote de 1605).

4- Quijote II, 71, p. 853.

5- Quijote II, 39, p. 666.

6- Arturo Marasso, Cervantes, La invención del "Quijote", s/f.

7- Si bien el grueso de la obra de Marasso centra su trabajo en el conocimiento de Virgilio por parte de Cervantes, se debe destacar también el que haya estabelecido correspondencias entre Cervantes y Aristófanes, Quintiliano, Plinio, Horacio, Aristóteles y Platón.

8- Marasso suele confrontar el texto cervantino con las traducciones al español más antiguas de los autores clásicos. Las primeras ediciones de los clásicos en lengua romance fueron brillantemente esquematizadas por R.R. Bolgar en The classical heritage and its beneficiaries from the carolingian age to the end of the renaissance, 1964. Tal como lo demuestra el cuadro sinóptico de Bolgar, las primeras traducciones de la Eneida al español, francés o italiano son muy previas a Cervantes y su obra. Según el registro de A. Pellicer en su Bibliotheca de Traductores Españoles la primeira traducción de la Eneida habría sido hecha por Don Henrique de Aragón en 1428. Obviamente esta primera traducción no fue la más difundida. En francés habria una paráfrasis anónima ya en 1483 , mientras que la primera traducción al italiano habría sido responsabilidad de Atanágoras Graecus en 1476.

9- Cf. al respecto mis dos trabajos "Parodia cervantina del mito de Orfeo", y "Don Quijote y Teseo en el laberinto ducal".

10- Quijote II, 44, p. 695.

11- Quijote II, 44, p. 695.

12-P. Virgilio Maron, Eneida, Canto IV, vv. 9/11.

13- Eneida IV, 20/23.

14- Quijote II, 44, p. 695.

15- Eneida IV, vv. 31/38.

16- Eneida IV, vv. 
17- Quijote II, 44, p. 698.

18-Quijote II, 44, p. 695.

19-Quijote II, 44, p. 696.

20-Quijote II, 44, p. 696.

21-Quijote II, 44, p. 697.

22- Quijote II, 44, p. 698.

23- Eneida I, vv. 565/566.

24- Eneida I, vv. 615/618.

25-Quijote II, 44, p. 698.

26- Eneida IV, vv. 68/73.

27-Eneida IV, w. 1/2.

28-Quijote II, 44, p. 697.

29- Homero mostró en su Ilíada como Eneas, si bien no tuvo un papel tan relevante como los de

Agamenón, Héctor, Menelao, Paris y Aquiles, en la guerra de Troya, fue, no obstante, un guerrero de notable distinción Favorito de ciertos dioses, se ven a sus descendientes como llamados a reinar sobre la Troade. Quizás lo único que le habría faltado al Eneas homérico para alcanzar gloria eterna fuera la muerte en heroico combate.

30- Quien quiera estudiar como aparece la figura de Eneas en ciclos épicos post-homéricos puede consultar el artículo de Nicholas Horsfall, 1979, p.372-90.

31- Naevius. Belli Punici Carminis, fragmento 14-23.

32- Virgilio escribió la Eneida en el llamado "siglo de Augusto". Esta obra que presentaba los origenes de Roma y su grandeza debia, obviamente, adoptar una posición muy firme y distinta frente a versiones de la leyenda de Eneas que fuesen críticas con la figura de este héroe. Nadie podría imaginar una epopeya nacional en la cual se hiciese "padre de la raza" a un traidor.

33- La versión virgiliana de la historia de Dido y Eneas fue adoptada entre otros por Tito Livio, Dioniso de Halicarnaso, Ovidio, Silio Itálico, Marcial y Juvenal. Lo que se conoce como versión de Justino es la que mantiene separadas cuidadosamente las dos leyendas. Si bien se la llema "versión de Justino" porque encontró su forma canónica en la Historia Universal de aquel autor, escrita a fines del siglo II d.C. esto no quiere decir que hasta ese entonces no se hubiesen suscitado controversias ante la versión propuesta por el mantuano. Ya en el mismo siglo de Augusto Ateyo Pretextato y Veleyo Patérculo criticaron la fusión legendaria virgiliana. Se inscriben en esta línea numerosos autores, muchos de ellos cristianos (Tertuliano, Minucio Felix, Eusebio de Cesárea, Ausonio, Servio Honorato, San Jerónimo y Prisciano) quienes hicieron de Dido un símbolo de la mujer fiel y casta, pues tras la muerte de su primer marido no volvió a casarse y porque es mentira todo lo referido a su encuentro y amor con Eneas.

34- Las inscripciones sepulcrales en latín pertenecen una a Guillermo Bcrenguer (1057-1060) hallada en el santuario de San Miguel de Fay y la otra a Sancho el Fuerte (muerto em 1072) en el monasterio de Oña.

35- En ella se refería la fundación de Toledo por dos descendientes de los troyanos.

36- Amancio Labandeira, 1984.

37- Eneida I, vv. 378-380.

38-Quijote II, 44, p. 698.

39- Suzanne Guillou-Varga, 1986.

40- Consúltese Alfred Cary Schlessinger, 1937, p. 234.

41-Quijote II, 57, p. 772.

42-Quijote II, 57, p. 772.

43- Quijote $\amalg, 57$, p. 772. 
44- Consúltese A. Salazar, 1948, p. 161.

45- Digo "peor de los casos" no porque haya una configuración textual mejor que otra sino porque contemplo que, si postulo la existencia de una parodia, ésta, obviamente, responde a intenciones codificadoras del autor, el cual espera que sus lectores las decodifiquen.

46- Quijote II, 57, p. 772.

47- Catulle, Poésies. Carmen LXIV v. 133.

48- Eneida IV, vv. 305-306.

49- Quijote II, 57, p. 772.

50- Carmen LXIV v. 183.

51- Ovidio, Heroidas. Heroida X, v. 35.

52- Eneida IV, v. 314.

53- Eneida IV, vv. 333-336.

54- Eneida IV, vv. 360-361.

55-Quijote II, 58, p. 775.

56-Debo este dato a la obra de Arturo Marasso citada supra.

57-Quijote II, 69, p. 844.

58-Eneida VI, vv. 456-458.

59- Eneida VI, vv. 465-466.

60- Eneida VI, vv. 469-474.

61- Pienso aquí en aquella distinción platónica entre la música que es verdaderamente un arte porque copia directamente del mundo de las ideas, y las demás artes que están condenadas a copiar de copias.

62-Quijote II, 71, p. 853.

63- Toda la primera parte, en sus historias intercaladas, al igual que un sinnúmero de aventuras y episodios del Quijote de 1615 se presentan como si se estuviera ante una gran casuística amorosa. Muchos de esos episodios son reducibles a fórmulas en las cuales el amor se opone a diferentes intereses: la razón de estado, el poder, la condición social, la familia etc.

64-Don Quijote lo compone para responder al primer romance que Altisidora le dirige. 65- Quijote II, 46, p. 706-707.

66- Utilizo el término "platonismo" con comillas pues si bien es un concepto estructurante de la cosmovisión de Don Quijote, es dificil dilucidarlo puesto que pueden darse sutiles variaciones según adscribamos a tal o cual teorizador.

67- Centrados en una perspectiva lingüistica y en el conocimiento de la realidad pueden ser de utilidad el artículo de Alexander Parker, 1948, p. 287-305, y el capítulo de Richard Predmore "La realidad" en El mundo del "Quijote".

68- Una perspectiva actualizada al respecto puede encontrarse en Michel Moner, 1986.

69- Cervantes suele presentar personajes que se regeneran (piénsese, por ejemplo, en el Don Fernando de la primeira parte), pero tal regeneración se da a partir del elemento bueno que hay en ellos (véase el caso de Teodosia, personaje de Las dos doncellas - debo esta importante indicación a la profesora Alicia Parodí).

70-Quijote II, 64, p. 823.

71- Para una interpretación cristiana de la trayectoria de Eneas puede consultarse Francis A. Sullivan, 1959, p. 150-61.

72- Quijote II, 74, p. 865. 


\section{Referências Bibliográficas}

BOLGAR, R. R. The classical heritage and its beneficiaries from the carolingian age to the end of the renaissance. Harper Torchbooks, The Academy Library, 1964.

CATULLE. Poésies. Trad. de Georges Lafaye. Paris: Les Belles Letres, 9 ed. rev., 1974.

GUILLOU-VARGA, Suzanne. Mythes, mythographies et poésie lyrique au siècle d'or espagnol. Paris-Lille: Université de Lille III/Difusion Didier Erudition, 1986.

HORSFALL, Nicholas. Some problems in the Aeneas legend. Classical Quarterly, Oxford, v. $24, n^{\circ} 2$, p. 372-90, 1979.

LABANDEIRA, Amancio. Estatuto y función de dos personajes mitológicos: Dido y Eneas en la literatura española del Siglo de Oro. Le personnage dans la littérature du siècle d'or: statut et fonction. Paris: Recherches sur les civilisations, 1984.

MARASSO, Arturo. Cervantes. La invención del "Quijote". Buenos Aires: Biblioteca Nueva, Colección Academus, s.d.

MONER, Michel. Cervantes: Deux thèmes majeurs (l'amour — les armes — les lettres). Paris: France Ibérie Recherche, 1986.

OVIDIO. Heroidas. Introducción, versión rítmica y notas de Tarsicio Herreza Zapien. Bibliotheca Scriptonum Graeconum et Romanarum Mexicana. México: UNAM, 1979.

PARKER, Alexander. El concepto de verdad en el Quijote. Revista de Filología Española, t. 32. p. 287-305, 1948.

POZUELO, José María La recepción de Virgilio en la teoría literaria española del siglo XVI. Actas del I Simposio Virgiliano conmemorativo del bimilenario de la muerte de Virgilio. Universidad de Murcia.

PREDMORE, Richard L. An Index to Don Quijote. Including proper names and notable matters. New Brunswick: Rutgers University Press, 1938.

SALAZAR, A. Música, instrumentos y danzas en las obras de Cervantes. Nueva Revista de Filologia Hispánica, v. 2, p. 161, 1948.

SCHLESSINGER, Alfred Cary. Identification of parodies in Aristophanes. American Journal of Philology, Baltimore, v. 58, $\mathrm{n}^{\circ} 3,1937$.

SULIVAN, Francis A. The spiritual itinerary of Virgil's Aeneas. American Journal of Philology, Baltimore, v. 80, no 2, 1959, p. 150-61.

VILA, Juan Diego. Parodia cervantina del mito de Orfeo. Actas II Congresso Argentino de Hispanistas. Mendoza: Universidad Nacional de Cuyo/Asociación Argentina de Hispanistas, 1989, t. II, p. 291-307.

VILA, Juan Diego. Don Quijote e Teseo en el laberinto ducal. Actas II Coloquio Internacional de Cervantistas (nov. 1989). En prensa.

VIRGILIO MARON. Eneida. Introducción, versión rítmica y notas de Rubén Bonifaz. Bibliotheca Scriptorum Graeconum Latinarum Mexicana México: UNAM, 1972. 
VILA, J. D. Didon et Énée dans le Quichotte de 1615. Clássica, São Paulo, 4: 185-202, 1991

RÉsumÉ: Bien que la connaissance, dans roeuvre de Cervantès, des versions de l'Enéide du siècle d'or espagnol soit communément créditée par la critique, il n'a pas eu d'études qui mettent en valeur, d'une manière adéquate, la nature d'une telle réélaboration. Nous nous centrons, dans cet article, dans la parodie des amours de Didon et Énée, réalisée par Cervantès dans la deuxième partie de son oeuvre, à travers les personnages Altisidore et Don Quichotte. Structurée tout au long de trois moments-clés et liée au traitement de deux autres mythes - celui de Thésée et Ariane et celui d'Orphée et Eurydice - cette analyse prétend une relecture qui prenne en compte la valeur du poème de Virgile dans la conformation de ce roman. MOTS CLÉs: Cervantès, Don Quichotte, Virgile, Enéide, Didon et Énée, littérature comparée. 